\title{
Eruptive xanthomatosis
}

\author{
ATIF MUNIR, ${ }^{1}$ JEHANGIR ABBAS²
}

\section{Background}

A 33-year-old woman with diet-controlled type 2 diabetes presented with pruritic yellow erythematous papules on her back, arms, legs and buttocks (Figure 1). Glycaemic control had gradually deteriorated over the last one year with a $\mathrm{HbA}_{1 c}$ reaching $134 \mathrm{mmol} / \mathrm{mol}$. The non-fasting lipid profile had deteriorated acutely from being on-target to a total cholesterol level of $21 \mathrm{mmol} / \mathrm{L}$ and triglycerides of $69 \mathrm{mmol} / \mathrm{L}$.

Figure 1 shows severe xanthoma usually seen with a genetic disorder, which may or may not be exacerbated by diabetes or hypothyroidism. Such cases require appropriate investigation, including exploration of family history, alcohol use and ApoE genotyping. Treatment differs according to the underlying diagnosis. Figure 2 demonstrates lipaemia retinalis in the same patient.

\section{Pathology}

Eruptive xanthomatosis is a papular cutaneous manifestation of hypertriglyceridaemia which can occur due to a primary genetic defect, or secondary to another disorder such as diabetes, hypothyroidism, liver cirrhosis, nephrotic syndrome or alcohol excess. ${ }^{1}$ A xanthoma is a dermal deposition of lipid-rich macrophages. Eruptive xanthomas normally resolve rapidly and completely with treatment of the underlying disorder.

In the context of diabetes, hypertriglyceridaemia occurs due to reduced chylomicron clearance leading to an increase in very low density lipoproteins, or lack of insulin (or insulin resistance) resulting in an acquired lipoprotein lipase deficiency. ${ }^{2}$ Hypertriglyceridaemia needs to be excluded in patients who present with lesions having characteristics of eruptive xanthomas. Management in the context of diabetes should focus on adoption of a low-fat diet, weight reduction and rapid improvement of glycaemic control before considering the use of fibrates or statins. ${ }^{3}$ Severe hypertriglyceridaemia is associated with increased risk of pancreatitis and requires urgent treatment.

Consultant Diabetologist and Endocrinologist, Royal Victoria Infirmary, Queen Victoria Road, Newcastle upon Tyne, UK

2 Specialty Trainee, Diabetes and Endocrinology, Royal Victoria Infirmary, Newcastle upon Tyne, UK

Address for correspondence: Dr Atif Munir Royal Victoria Infirmary, Queen Victoria Road, Newcastle upon Tyne, NE1 4LP, UK.

Tel: +44 (0)1912823439

E-mail: atif113_2000@yahoo.co.uk

Br J Diabetes Vasc Dis 2015;15:142

http://dx.doi.org/10.15277/bjdvd.2015.025
Figure 1. Pruritic yellow erythematous papules

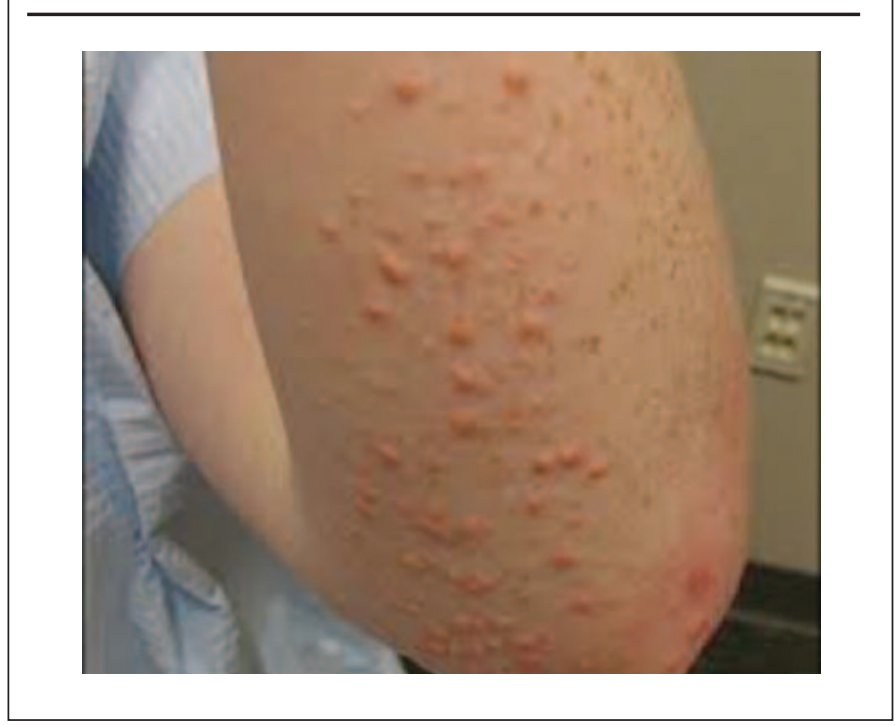

Figure 2. Lipaemia retinalis in the same patient

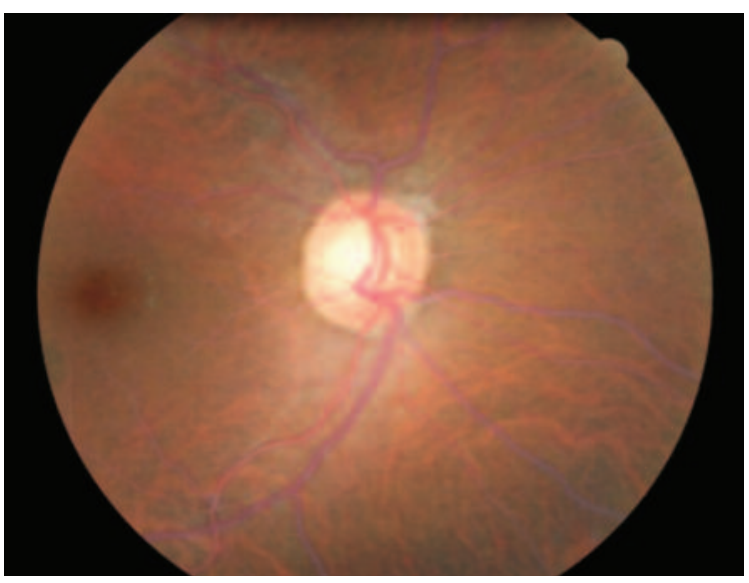

\section{Conflict of interest None \\ Funding sources None}

\section{References}

1. Lugo-Somolinos A, Sánchez JE. Xanthomas: a marker for hyperlipidemias. Bol Asoc Med P R 2003;95:12-6.

2. Chahil TJ, Ginsberg HN. Diabetic dyslipidaemia. Endocrinol Metab Clin North Am 2006;35:491-510.

http://dx.doi.org/10.1016/j.ecl.2006.06.002

3. Crowe MJ, Gross DJ. Eruptive xanthoma. Cutis 1992;50:31-2. 